\title{
複数候補べクトルを用いた半画素精度 動きベクトル検出
}

野 中雅 ${ }^{\dagger}$, 正会員松尾明 彦 ${ }^{\dagger}$ 中 井敏 久 ${ }^{\dagger}$

\section{1. まえ がき}

動画像符号化の標準のひとつに MPEG 2 がある. MPEG 2 は比較的高いビットレートをターゲットと しており，また放送への応用も考元られるめ, CCIR Rec.601 以上の解像度の画像を扱う場合が多 い.

94 年 3 月には MPEG 2 の DIS (Draft International Standard $)^{1)}$ が完成し, 現在これに対応したLSI の開 発も行われてきている. MPEG 2 の圧縮アルゴリズ ムは動き補償フレーム間予測と DCT によるハイブリ ッド符号化であり, MPEG 1・H.261 の符号化アルゴ リズムと基本的には同じである。しかしながら，より 高品質な画像を扱うため処理に要する演算量が非常に 多くなっており, 特に動き補償フレーム間予測におけ る動きべクトル検出のための演算量の増加が, ハード ウェア化の際の問題点となっている.また, MPEG 2 では動き補償に半画素精度の動きべクトルが扱え, よ り高能率な符号化が可能となっているが, 単純に半画 素精度の動きべクトル検出を「全点探索法」で行うと, さらに 4 倍の演算量が必要になる.

このため, MEPG 2-Test Model 4(以後 TM 4 と記 す) 2)では, 第 1 段階で 1 画素精度の探索を行い, 第 2 段階では第 1 段階で検出したべクトルの周辺のべク トルだけを半画素精度で探索するすることにより, 演 算量の削減を行っている。しかしながら, ハードウェ アの小型化の要求から, さらなる演算量の削減が求め られている.

すでに, 演算量を削減しても動きベクトルの誤検出

†沖電気工業株式会社 関西総合研究所

"Half-pel Motion Vector Search by Plural Cadidates"

by Masato Nonaka, Akihiko Matsuo and Toshihisa Nakai (Oki Electric Industry Co., Ltd, Osaka)
を少なくする方式として，第1 段階でサブサンプルし た解像度の低い画像の全点探索により複数の候補べク トルを検出し，第 2 段階で第 1 段階で検出した複数の 候補ベクトルのみに対し, 元の解像度で画像の動き検 出を行う方式も提案されている31.

本稿では, 第 1 段階で解像度の低い画像の 1 画素精 度の探索により複数の候補ベクトルを検出し, 第 2 段 階で第 1 段階で検出した複数の候補ベクトルの周辺べ クトルのみに対し, 元の解像度の画像で半画素精度の 動きべクトル検出を求める方式を提案し検討する.

計算機シミュレーションの結果は, 提案方式によれ ば TM 4 の $1 / 3$ の演算量で, TM 4 と同等の特性が得 られることを示している。

\section{2. 半画素精度の動きベクトル検出}

\section{1 全点探索による動きべクトル検出}

一般に, 動きベクトルはブロックマッチングを基本 とした方式によって検出される.

「全点探索法」とは, 現フレームの基準ブロック $(M$ $\times N$ 画素) と, 前フレームのベクトル探索範囲内に存 在するすべての基準ブロックと同じ大きさの参照ブロ ックとを比較(ブロックマッチング)し, 類似度の最も 高い参照ブロックと基準ブロックとの位置関係(動き ベクトル)を求める方式である4).

現フレームの画素を $X(m, n)$, 前フレームの画素 を $Y(m, n)$ とすると, 類似度の評価は次式で示され る絶対誤差 $D(i, j)$ で行われることが多い。

$$
D(i, j)=\sum_{m=1}^{M} \sum_{n=1}^{N}|X(m, n)-Y(m+i, n+j)|
$$

ここで, $D(i, j)$ が最小となる場合のベクトル $(i, j)$ が 動きベクトルになる．

半画素精度の動きベクトル検出は, 前フレーム画像 において半画素位置のデー夕を, 隣接する整数画素位 
置のデータの平均で生成し, これと現フレームの整数 画素位置のデー夕を(1) 式に入力することで行う.

1 個のベクトルの類似度の評価には差分, 累計抒よ び絶対値演算が行われ,これらの演算量は 2.5 回の加 算演算に相当する。（1)式の評価を行うべクトル（以 下, 試行べクトルと呼ぶ)の数を $S$ 個とすると, $M \times$ $N$ 画素サイズのブロックの動きべクトルの検出には $2.5 \times M \times N \times S$ 回の加算に相当する演算量が必要と なる.ベクトル探索範囲を \pm 15 画素(ライン)とする と試行ベクトル数は 3844 個になるため, ブロックサ イズが $16 \times 16$ 画素の場合, 半画素精度のベクトル検 出に必要な演算量は $2,460,160$ 回の加算相当になる. 1 フレームの画像サイズが 704 画素, 480 ラインで, フレームレートが $30 \mathrm{~Hz}$ とすると, これをリアル夕 イムに処理する動きべクトル検出器には約 100 GOPS の演算能力が必要になり,この演算量が 1 chip の LSIでの実現を困難にしている.

\subsection{MPEG 2-Test Model の動きべクトル検出}

前節で説明したように, 半画素精度動きべクトル検 出には膨大な演算量が必要であるため, TM 4 では「2 段階検出法」〔方式 1〕を用いて演算量の削減を図って いる.

水平方向の半画素精度ベクトル $(i+0.5, j)$ に対する 類似度の評価演算を考えると, (1) 式は次式のように なる。

$$
\begin{aligned}
& D(i+0.5, j) \\
& =\sum_{m=1}^{M} \sum_{n=1}^{N}|X(m, n)-Y(m+i+0.5, n+j)| \\
& =\sum_{m=1}^{M} \sum_{n=1}^{N} \mid X(m, n)-\frac{1}{2}(Y(m+i, n+j) \\
& \quad+Y(m+i+1, n+j)) \mid
\end{aligned}
$$

一般にフレーム内の画素間の相関は強いため5)

$$
Y(m+i, n+j) \simeq Y(m+i+1, n+j)
$$

といえる.したがって, 整数画素精度の探索で類似度 が高いとされたベクトルから半画素ずれたベクトルの 類似度は高くなると考えられる。

この性質を利用し, TM 4 では第 1 段階では整数画 素精度のベクトル探索を行い, 第 2 段階ではこの中で 最も類似度の高いべクトル(候補ベクトル)の周辺 8 点 に対し半画素精度の動きべクトル評価を行い, 最後に 候補ベクトルを含めた 9 個の試行ベクトルの中で, 最 も類似度の高いべクトルを動きベクトルとして出力し ている、TM 4 を実現するための演算量は, 前節と同 じ条件(ブロックサイズ,探索範囲)の場合, 第 1 およ び 2 段階の試行ベクトル数の合計が 969 個 $\left(31^{2}+8\right.$ 個 $)$ となり,「全点探索法」と比較して約 $25 \%$ の演算量と
なる。

しかしながら LSI 化を考えた場合，この演算量は 依然大きな值であり,さらなる削減が望まれる。ま た， 2 段階検出では第 1 段階の他の試行ベクトルの評 価值が候補ベクトルの評価值と大きな差がない場合に は, 半画素位置のデータを隣接する画素 ( ( 2) 式, $Y(m+i+1, n+j))$ との平均で生成するため, 半画素 精度での動きべクトル検出では, 候補べクトル以外の ベクトルの近傍の方が, 類似度が高くなることが考え られる.このような時, 真の動きべクトル (全点探索 で求まる動きべクトル)を検出することができなくな り，符号化効率に影響してしまう.

\section{3. 複数候補ベクトルによる多段階検出}

\section{1 間引きによる縮小画像を使用した方式}

「多段階検出法」における動きべクトルの誤検出は 候補ベクトルを 1 本に絞っていることが原因であり, これは候補ベクトル数を複数にすることで改善でき る.

今回, 次に示す方式〔方式 2〕について検討を行っ た.

- 第 1 段階：1 画素精度の動きベクトル検出を行 い, 類似度が高いと評価された複数のベクトルを 候補ベクトルとして選択する。

-第 2 段階：候補ベクトル周辺に対し半画素精度の 動きベクトル検出を行い動きベクトルを得る。

以上の検出動作を図 1 に示す.

〔方式 2〕では候補ベクトルを複数にしているため, 第 1 段階での動きべクトル検出を簡略化しても第 2 段 階で補償されると考えられる.そこで, 第 1 段階の検

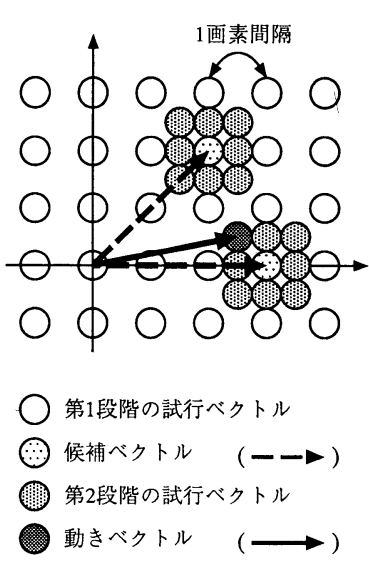

図 1 候補ベクトルを複数にした方式 Vector search by plural cadidates.

テレビジョン学会誌 Vol. 49, No. 2 (1995) 
出にはブロック内の全画素を用いる〔方式 $2 \mathrm{a}$ ], サブ サンプリングにより水平方向の画素数を $1 / 2$ に削減す る〔方式 $2 \mathrm{~b}$, 同じく水平垂直方向共に画素数を $1 / 2$ に削減する〔方式 $2 c$ 〕を比較する.

画素間の相関が強い場合, 第 2 段階における評価結 果は基本的に第 1 段階の評価に準じると考えられるた め, 第 1 段階での評価値の最小值より大きく外れる評 価值となった試行べクトルの周辺に, 真の動きベクト ルが存在する可能性は低い。したがって，第 1 段階の 動きべクトル検出の評価値 $D(i, j)$ の最小值を元に閾 值を決め, 評価值 $D(i, j)$ が閾值以下になるべクトル をすべてを候補べクトルにすれば，最小值に近い評価 值を持つ試行べクトルをすべて候補べクトルにするこ とができる.

しかしながら, 以上の方法では最悪の状況を考える と, 第 1 段階の試行べクトルすべてを候補ベクトルに することになり現実性がなくなる．また，閾值が決定 してから候補べクトルを求めるため, 制御が複雑にな るという問題も発生する。このため, 本稿では第 1 段 階で類似度が高いとされた上位数個のべクトルを候補 ベクトルに選ぶ方式を採用する。

〔方式 $2 \mathrm{a} \sim \mathrm{c}$ 〕 TM 4 に記述されている方式〔方 式1〕とをシミュレーションにより比較した。

特性評価は, それぞれの方式で検出した動きべクト ルを(1) 式に当てはめ, 評価值 $D(i, j)$ を求めること で行った。評価值が小さい方がより類似度の高い動き
ベクトルを検出していることになる．これ以外に演算 量の比較も行った.

$$
\text { シミュレーション条件を表 } 1 \text { に示す. }
$$

候補ベクトル数の違いによる検出特性の変化を図 2 ( a ) （c ）に示す. ここで, 「全点探索法」の時の検 出結果を〔方式 0〕とし, 〔方式 1〕および〔方式 2〕 と比較して示す。〔方式 1〕は〔方式 $2 \mathrm{a}$ 〕で候補べク トルが 1 個の場合にあたる。図 2 で, 縦軸は (1) 式に よる評価最小值の 1 フレーム内の全マクロブロックに わたる平均, 横軸は候補べクトル数を表している.

図 2 より, 候補べクトル数を増加させることで評価 值が小さくなり, より類似度の高い動きべクトルを検 出していることがわかる. 特に, 第 1 段階でサブサン プリングを行っている〔方式 $2 \mathrm{~b}$ )，〔方式 $2 \mathrm{c}$ 〕では改 善効果が大きい。これは, 処理の簡略化により第 1 段 階の検出結果が必ずしも正しいものとはいえなくな り，第 2 段階で補償される場合が多くなっていること

表 1 シミュレーション条件

Simulation parameters.

\begin{tabular}{c|l}
\hline \hline 入力画像 & Flower garden, Football, Susie \\
\hline 処理フレーム & $1 \rightarrow 2$ frame（各シーケンス共） \\
\hline 候補ベクトル数 & $1,2,4,8,16$ 個 \\
\hline 評価方法 & $\begin{array}{l}1 \text { フレームすべてのマクロブロックの評価值の } \\
\text { 平均 }\end{array}$ \\
\hline
\end{tabular}

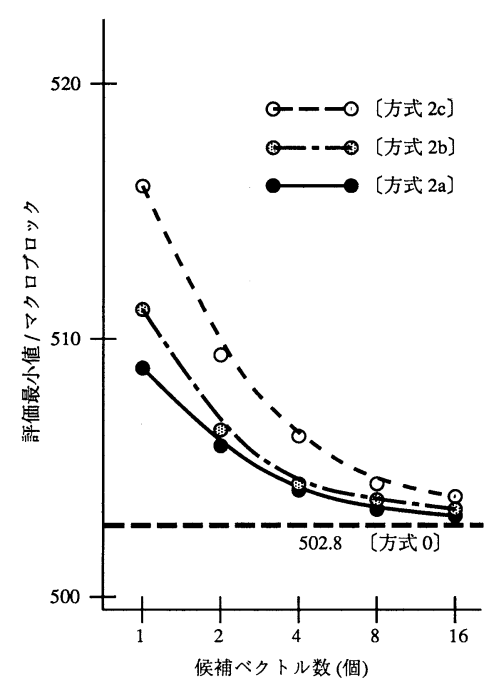

(a) Susie

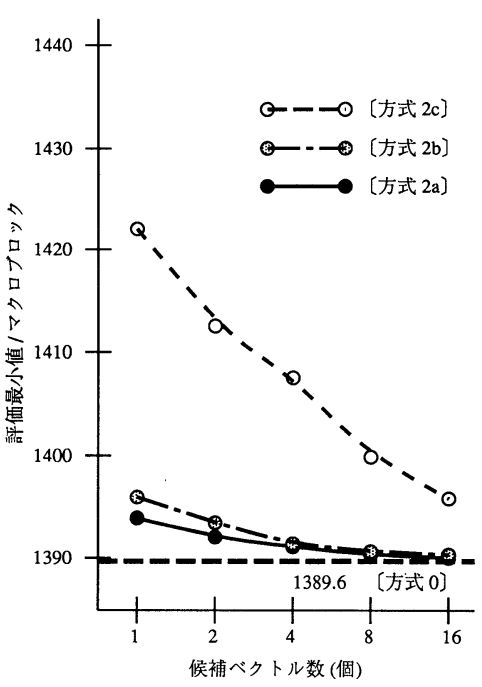

(b) Flower garden

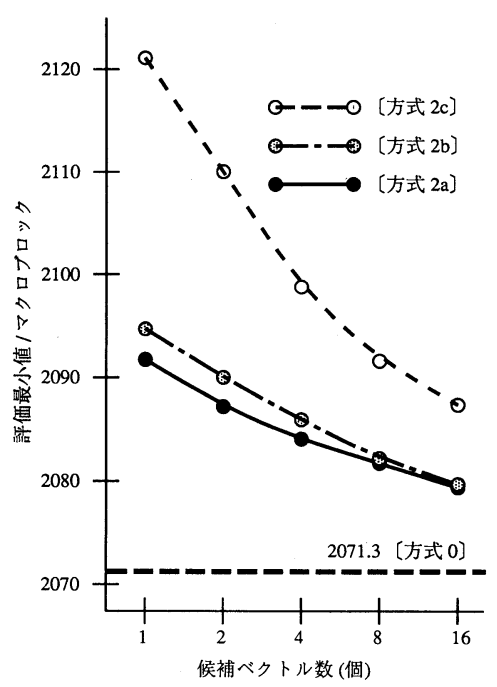

(c) Football

図 2 候補ベクトル数による特性変化 Performance of method 2. 
を示している.ブロックマッチングに用いる画素数が 少なくなるに従い, この傾向は強くなっている. 候補 ベクトル数を増加させるに従い各方式の差は小さくな っており, 複数の候補ベクトルを持つことで, サブサ ンプリングが原因の誤検出が抑えられている。また， 候補ベクトル数を増加させるに従い, 改善効果が小さ くなっていることがわかる。これは，第 1 段階におけ る類似度の順位の高い候補ベクトルの近傍に, 真のべ クトルの存在する場合が多いということを示してお り, 整数画素精度の探索で類似度が高いとされたべク トルから, 半画素ずれたべクトルの類似度は高くなる という前章の推測に沿った結果である.

表 2 に，〔方式1〕，〔方式2〕について演算量をま とめて示す.

本シミュレーションにより処理を $1 / 2 \sim 1 / 3$ 程度簡 略化しても, 候補べクトルを複数選ぶことで, TM 4 〔方式 1 と同等以上の特性を得ることができる ことを確認できた。

\subsection{4 画素平均による縮小画像を使用した方式}

〔方式 $2 \mathrm{c}$ 〕゙候補べクトル 8 個のときの各ブロック の評価最小值を図 3 に示す。この図において, $Z$ 軸 は〔方式 $2 \mathrm{c}$ による各ブロックの評価最小值と〔方式 0]による評価最小值との差分, $X Y$ 平面は画像の> レームを表している。

候補べクトルを増加させることで, ほとんどのブロ ックで〔方式 0〕と同じ評価最小值になるが, 一部のブ ロックでは依然大きな差が現れている，前節では，第 1 段階の動きべクトル検出に単純な間引きによるサブ サンプリング画像を用いていた. 図 3 で評価最小值に 大きな差が現れているブロックでは, サブサンプリン グで失われた画素によって差分が発生していた. 得ら

表 2 各方式における演算量（加算回数）

Number of operations for each method.

\begin{tabular}{|c|c|c|c|c|c|c|}
\hline & \multicolumn{6}{|c|}{ 候補ベクトル数 } \\
\hline & 0 (個) & 1 & 2 & 4 & 8 & 16 \\
\hline 方式 0 & $\begin{array}{r}(\text { 回 }) \\
2,460,160 \\
(397 \%)\end{array}$ & - & - & - & - & - \\
\hline 方式 $1,2 \mathrm{a}$ & - & $\begin{array}{l}620,160 \\
(100 \%)\end{array}$ & $\begin{array}{c}625,280 \\
(101 \%)\end{array}$ & $\begin{array}{l}635,520 \\
(102 \%)\end{array}$ & $\begin{array}{l}656,000 \\
(106 \%)\end{array}$ & $\begin{array}{l}696,960 \\
(112 \%)\end{array}$ \\
\hline 方式 $2 \mathrm{~b}$ & - & - & $\begin{array}{c}319,040 \\
(51 \%)\end{array}$ & $\begin{array}{c}330,560 \\
(53 \%)\end{array}$ & $\begin{array}{c}353,600 \\
(57 \%)\end{array}$ & $\begin{array}{c}399,680 \\
(64 \%)\end{array}$ \\
\hline 方式 2c & - & - & $\begin{array}{c}165,280 \\
(27 \%)\end{array}$ & $\begin{array}{c}176,800 \\
(29 \%)\end{array}$ & $\begin{array}{c}199,840 \\
(32 \%)\end{array}$ & $\begin{array}{c}245,920 \\
(40 \%)\end{array}$ \\
\hline
\end{tabular}

れた候補ベクトルにはサブサンプルで残った画素の情 報しか含まれていないため, 候補べクトル数を増加さ せることによる改善効果は期待できない.

そこで, 第 1 段階で隣接する 4 画素の平均による縮 小画像を用いる方式 〔方式 3) 検討した. 4 画素平均 で縮小画像を生成するため各画素の特徵的な情報は失 われるが，すべての画素情報を含んでいるため，図 3 に現れているような大きな差分の発生は抑えられると 考えられる。また，〔方式3〕では前フレーム画像に対 する縮小画像の生成は半画素位置のデー夕生成と同じ であるため, 現フレームに対してのみ縮小画像を生成 することになり, ハードウェア上の負担の増加は少な い.

〔方式 3〕について, 前節と同条件でシミュレーショ ンを行った。その結果を図 4 に示す。図 4 は図 3 と同 様に候補ベクトル数が 8 個の時の結果を各ブロックに ついて記したものである。

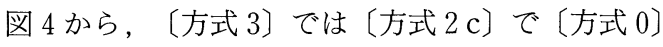
との評価最小值の差が大きくなっていたブロックが 〔方式0〕とほほ同じ值となり, 改善されていることが わかる. 一方, 平均により各画素の特徴が失われるこ とで, 僅かに劣化しているブロックも現れている. 次

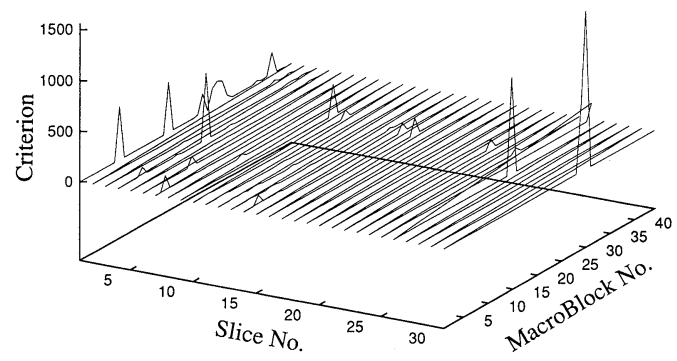

図 3 ブロック毎の評価值(方式 2c) Criterion of each block. (Method 2c)

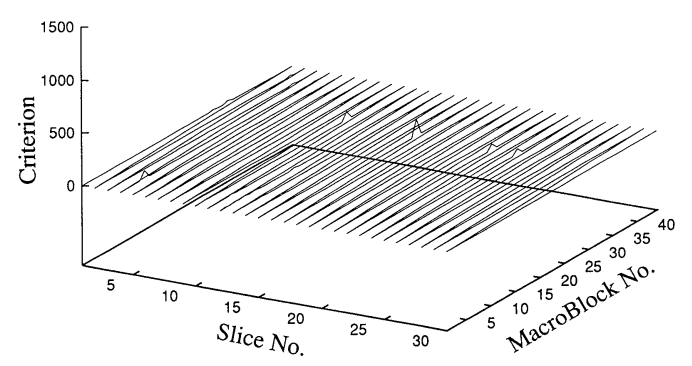

図 4 ブロック毎の評価値(方式 3 ) Criterion of each block. (Method 3)

テレビジョン学会誌 Vol. 49, No. 2 (1995) 


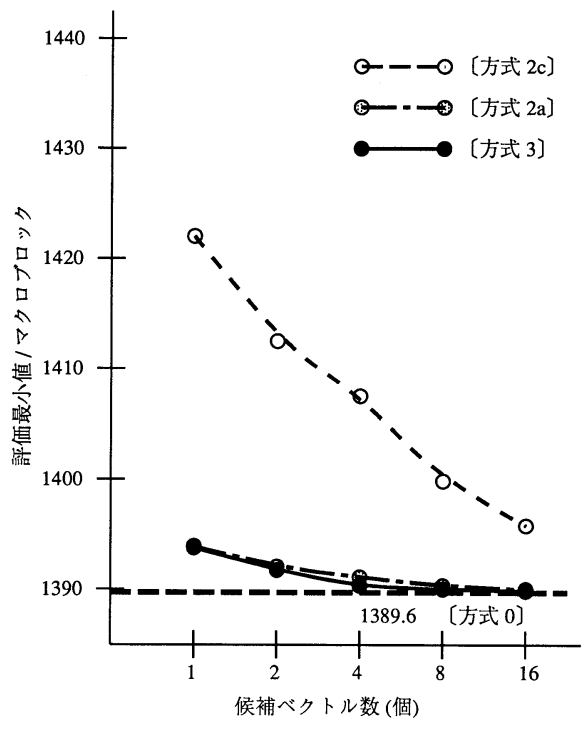

Flower Garden

図 5 方式 3 のベクトル検出特性 Performance of method 3.
縮小画像を用いた場合, TM 4 の 30\%の演算量 でTM 4 より類似度の高いべクトルを検出する ことができた。

今回は, 単純に評価値の小さい上位数個のベクトル を候補ベクトルとしたが, 評価值抢よびベクトルの值 から候補ベクトルを選択することで，より効率的な動 きべクトル検出が可能であると思われる. また, 今回 はフレーム単位の動きベクトル検出に絞って検討を行 ったが，今後フィールド単位の検出への適応も検討す る必要がある。

\section{〔参 考 文 献〕}

1) ISO-IEC/JTC 1/SC 29/WG 11: "ISO/IEC 13818-2 Draft International Standard" (1994)

2) ISO-IEC/JTC 1/SC 29/WG 11: "Test Model 4 (Draft)" (1993)

3）三宅, 堅田ほか：“動きベクトル検出方式の簡略化”,1993 年 画像符号化シンポジウム, pp. 151-152 (1993)

4）伊東晋, 竹村裕夫監修：“映像機器に抢けるディジ夕ル信号 処理技術”，pp. 35-39, トリケップス (1990)

5）吹抜敬彦：“画像のディジタル信号処理 増補版”, pp. 127132, 日刊工業新聞社 (1986)

6）仙田裕三：“半画素精度動きベクトル探索の簡略化方式”, 1994 年信学春大, D-339 (1994)

に,フレーム全体の特性を図 5 に示す。〔方式 3〕では 演算量を縮小画像を用いない[方式 2 a] の約 $1 / 3$ に削 減したにもかかわらず，ほぼ同等の特性が得られてい る。

\section{4. むす び}

本稿では, 半画素精度の動きべクトル検出で「2 段 階検出法」を用いる場合において, 第 1 段階のべクト ル探索に縮小画像を用い, ここで選択する候補べクト ルを複数にする方式を提案し，以下のことを確認し た。

・第 1 段階のベクトル検出にサブサンプルによる水 平方向 $1 / 2$ 縮小画像を用いた場合, TM 4 の 50〜 60\%の演算量で TM 4 よりも類似度の高い ベクトルを見つけることができた.

・第1段階のベクトル検出に平均值で作成した $1 / 4$

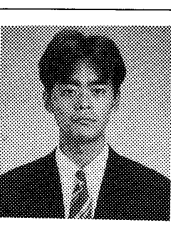

野中 初当人 昭和 62 年, 愛媛大学工学部 電子工学科卒業. 同年, 沖電気工業 (株) に入 社. 以来, テレビ電話・テレビ会議システム 抢よび画像処理用 LSI の研究開発に従事.

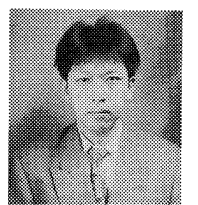

松尾踶明彦 平成 3 年, 神戸大学工学部シ ステム工学科卒業. 同年, 沖電気工業 (株) に 入社. 以来, 動画像符号化および画像処理関 連の研究開発に従事. 正会員.

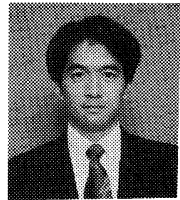

中井敏久昭和 58 年, 大阪府立大学工 学部電気工学科卒業. 同年, 沖電気工業(株) に入社. 平成元年, 南カリフォルニア大学修 士課程修了。情報理論・通信理論応用および 信号処理に関する研究開発に従事。 